\title{
16 al 19 de diciembre de 2016: temporal de levante en Baleares, Comunidad Valenciana, Murcia y Almería
}

https://doi.org/10.31978/639-19-010-0.497

\author{
José Manuel López Pérez'1 (jolopezp@aemet.es) \\ José Ángel Núñez Mora ${ }^{1}$ (jnunezm@aemet.es)
}

${ }^{1}$ AEMET / Delegación Territorial en la Comunidad Valenciana

\section{RESUMEN}

Este es el primero de los dos grandes temporales que se produjeron entre diciembre de $2016 \mathrm{y}$ enero de 2017, en el litoral mediterráneo español. Este episodio afectó a Baleares, la Comunidad Valenciana y Murcia además de la provincia de Almería.

Si bien los temporales de levante no son infrecuentes en estas zonas, lo que es menos habitual es la presencia de dos episodios en un periodo tan corto de tiempo, la época tan tardía (ambos en el invierno meteorológico) y la larga duración de los episodios, con dos fases claramente diferenciadas en ambos.

Durante estos días se produjeron precipitaciones generalizadas, muy abundantes, con intensidades moderadas, aunque puntualmente llegaron a ser fuertes o muy fuertes en los momentos más activos del temporal. Las lluvias fueron persistentes en el tiempo y dieron lugar a totales acumulados de precipitación muy importantes (entre la mitad y el total del valor climatológico anual de las precipitaciones en esas zonas).

Además, y como corresponde a todo temporal de levante, hubo vientos muy fuertes que dieron lugar a un fuerte oleaje con olas que superaron los 4 metros en gran parte del litoral y ocasionaron daños en la costa.

Se analizan las causas de la génesis del temporal y su desarrollo y algunos productos de modelos probabilísticos procedentes del Centro Europeo de Predicción a Plazo Medio, ya que cuando existe la probabilidad de que en los próximos días se puede desarrollar un temporal especialmente adverso, con serias consecuencias para las infraestructuras y cierto riesgo para la población, la cuantificación de esa probabilidad es una herramienta fundamental para orientar a las autoridades, a los responsables de protección civil y población en general.

PALABRAS CLAVE: temporal de levante; río de humedad; precipitaciones muy importantes; vientos muy fuertes; HRES-IFS; productos de modelos probabilísticos; EPS CEPPM; operatividad en el Sistema Nacional de Predicción.

\section{ORIGEN DEL TEMPORAL}

En niveles medio-altos de la troposfera el episodio se inicia con la aproximación por el oeste peninsular y en dirección norte-sur de una vaguada muy profunda con una anomalía de temperatura de $-28^{\circ} \mathrm{C}$ en $500 \mathrm{hPa}$ y con un máximo de viento posterior de $130 \mathrm{kt}$ en $300 \mathrm{hPa}$. 
AEMet. CNP GUIA TÉCNICA DE DIAGNÓSTICO NIVELES MEDIOS/ALLTOS DIA: 16/12/2016 A 12 UTC

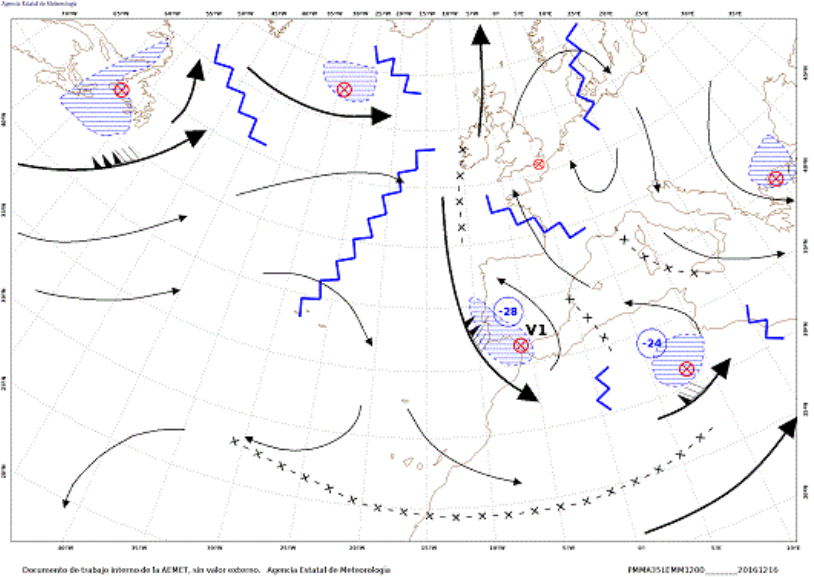

Figura 1. Guía técnica de diagnóstico de niveles medio-altos del 16 de diciembre a las 12 UTC.

Vaguada V1 con máximos viento de $100 \mathrm{kt} \mathrm{y}$ anomalía fría de $-28^{\circ} \mathrm{C}$ en $500 \mathrm{hPa}$ sobre el sur de Portugal y Andalucía occidental.

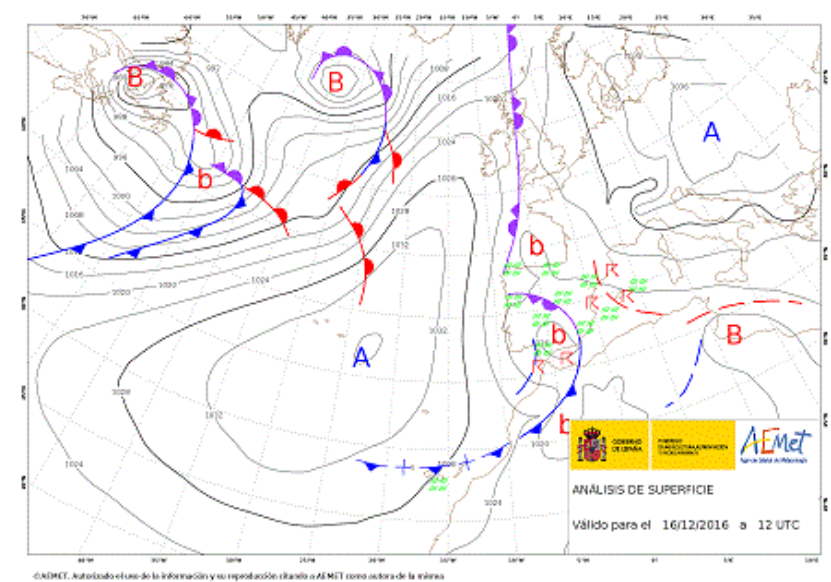

Figura 3. Análisis de superficie del 16 de diciembre a las 12 UTC, donde destacan el anticiclón de Azores y el de Centroeuropa con un frente frío desplazándose sobre Andalucía y Marruecos.

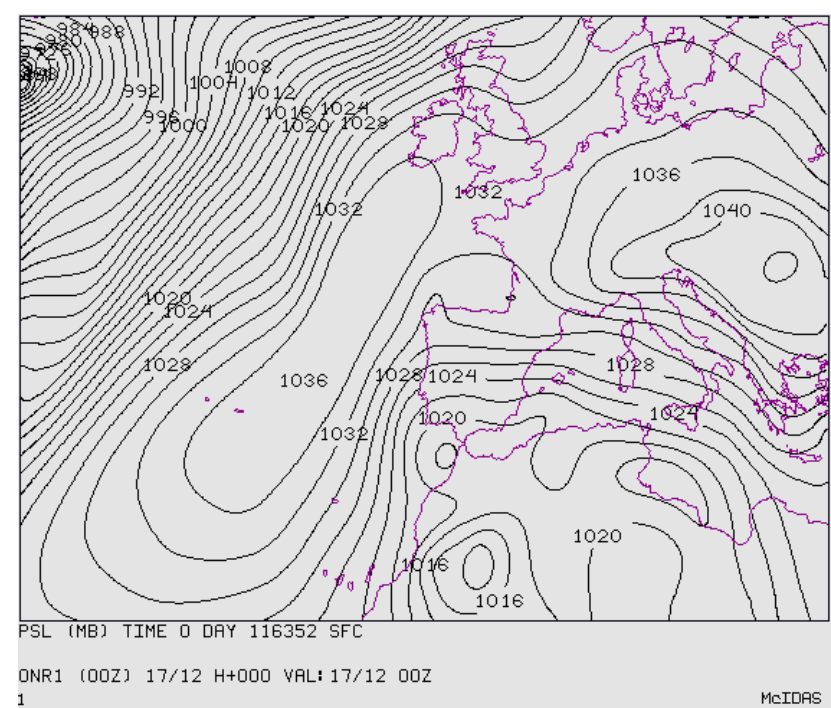

Figura 5. Análisis de presión en superficie del día 17 de diciembre a las 00 UTC.
AEMet. CNP GUIA TECNICA de DIAGNOSTICO NIVELES MEDIOS/ALLTOS DIA: 19/12/2016 A 12 UTC

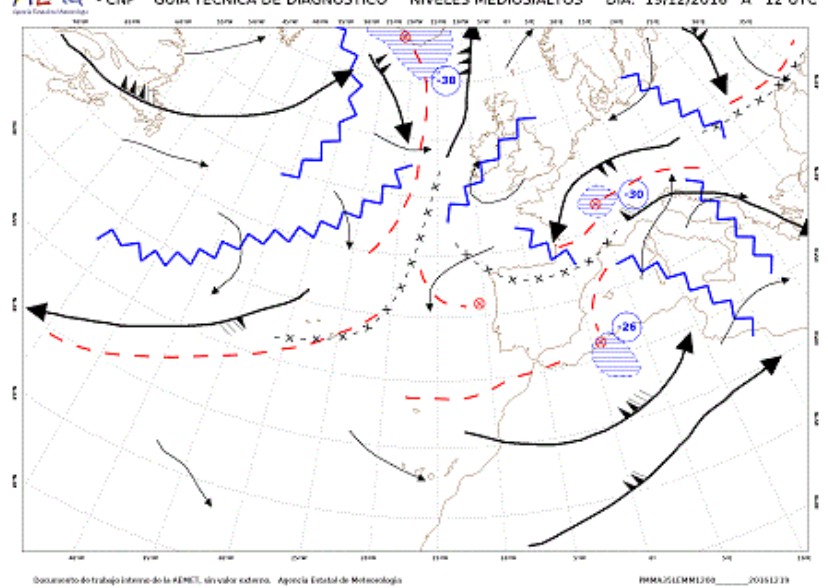

Figura 2. Guía técnica de diagnóstico niveles medio-altos del 19 de diciembre a las 12 UTC. Anomalía fría de $-26^{\circ} \mathrm{C}$ en $500 \mathrm{hPa}$ sobre Argelia.

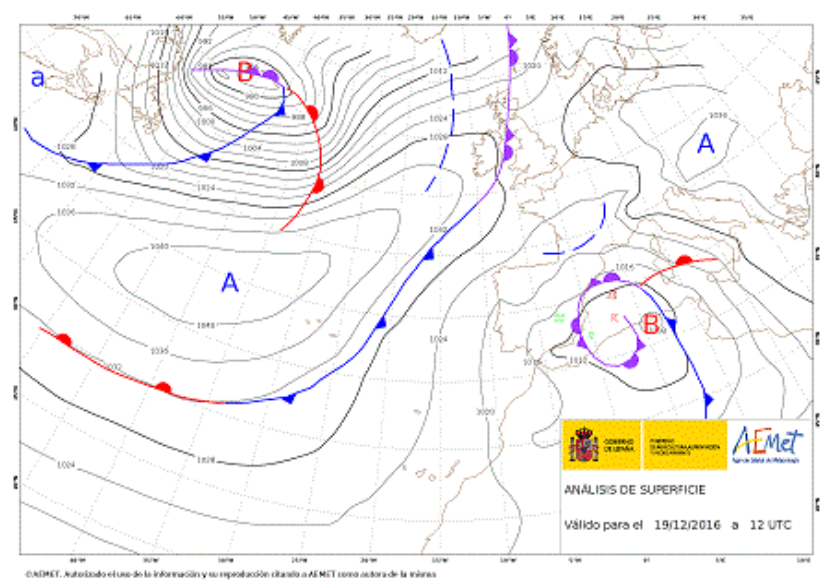

Figura 4. Análisis de superficie del 19 de diciembre a las 12 UTC con la baja situada sobre Argelia y restos del frente ya ocluido sobre las costas de Valencia y Murcia.

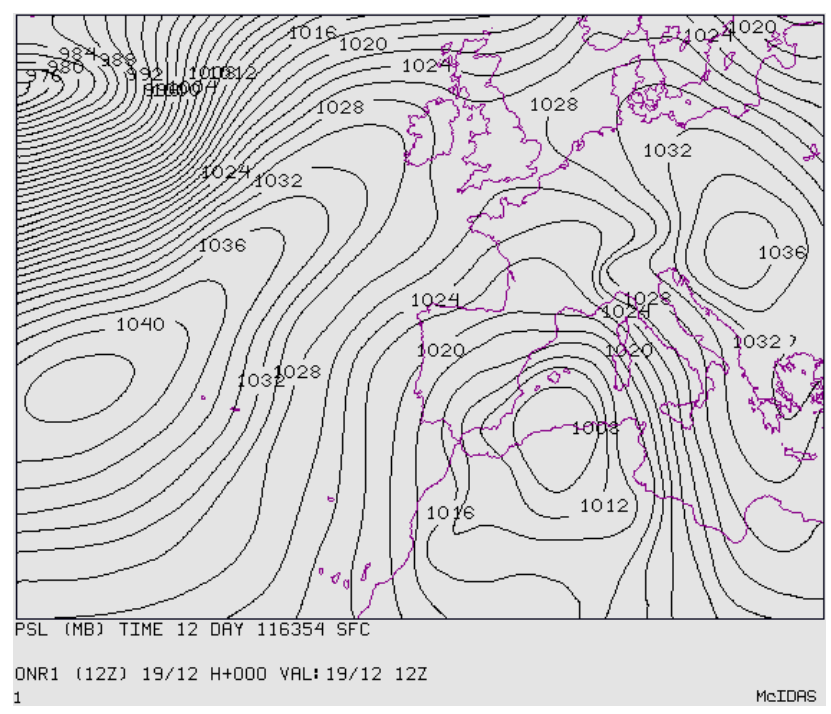

Figura 6. Análisis de presión en superficie del día 19 de diciembre a las 12 UTC. 
La vaguada origina una formación de bajas presiones en superficie, primero en Andalucía y el estrecho de Gibraltar, para acabar focalizándose a sotavento del Atlas, en el sur de Marruecos, con 1014 hPa de presión en superficie a las 00 UTC del día 17.

En Gran Bretaña y Centroeuropa las altas presiones relativas en superficie se refuerzan hasta los $1038 \mathrm{hPa}, \mathrm{y}$ se mantienen sin cambios significativos durante todo el temporal, mientras que la baja situada en Marruecos se profundiza ligeramente hasta $1012 \mathrm{hPa}$, y posteriormente se desplaza hacia el nordeste para profundizarse finalmente hasta $1004 \mathrm{hPa}$ y situarse sobre Baleares.

Entre estos dos centros de acción se canalizó un flujo de componente este, con recorrido marítimo a lo largo de todo el mar Mediterráneo, a partir de la tarde del viernes 16 y hasta el final del episodio, 5 días más tarde. Este flujo de levante, con más de 3000 km de recorrido sobre el mar, permitió un gran aporte de humedad, desarrollándose las precipitaciones más intensas en las zonas en las que incidía.

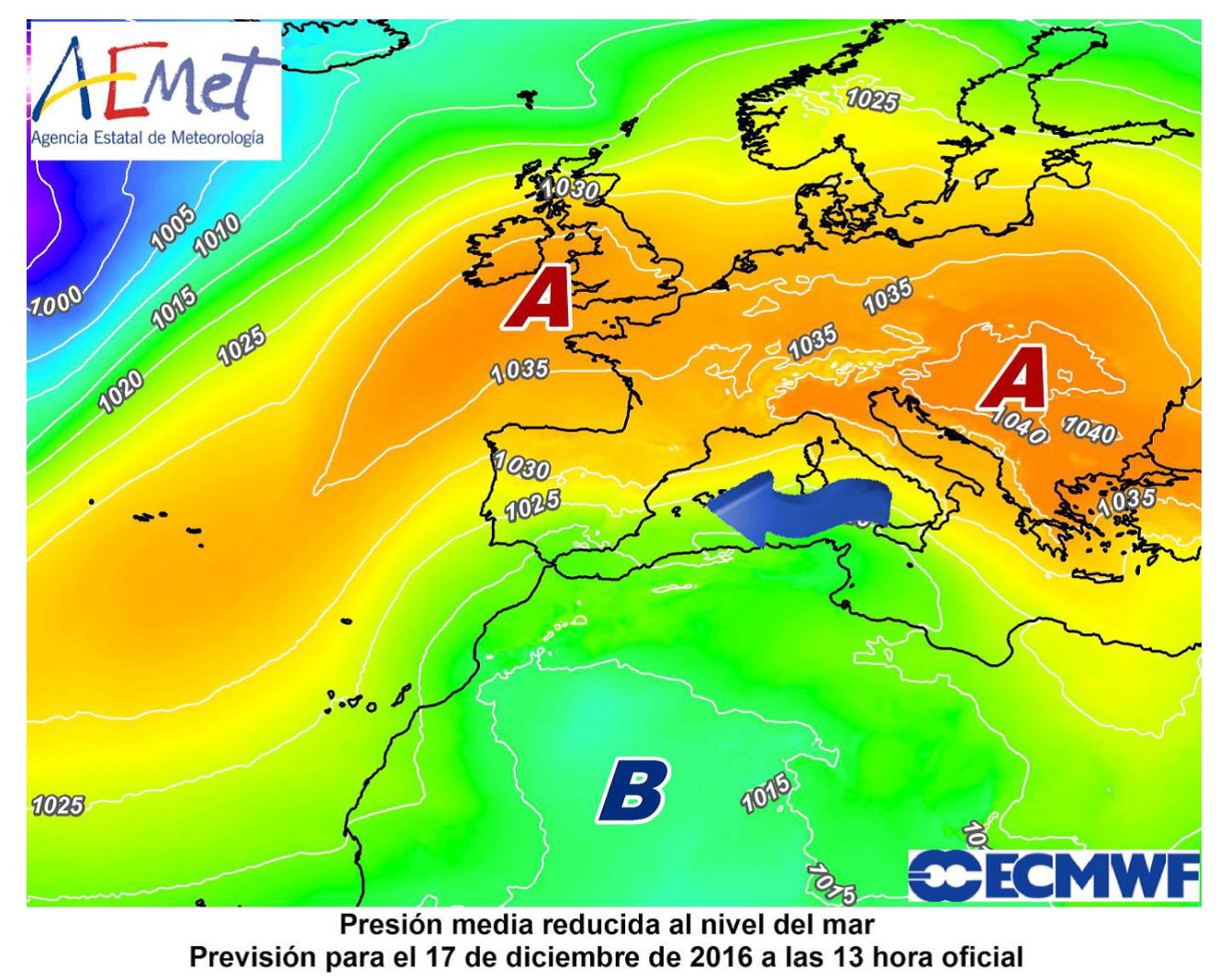

Figura 7. Modelo del Centro Europeo de Predicción Meteorológica a Plazo Medio (CEPPM/ECMWF). Presión, reducida al nivel del mar, prevista para el 17 de diciembre a las 12 UTC.

Este flujo de humedad se desarrolló en dos fases diferenciadas: inicialmente, el viernes 16 incidió sobre Baleares y el sur de la provincia de Castellón, desplazándose hacia el sur de la Comunidad Valenciana, Murcia y la provincia de Almería durante el sábado 17; a partir del domingo 18 y durante el lunes 19, en la segunda fase, la más adversa del temporal, realizó el mismo recorrido pero en sentido inverso. En el extremo meridional de la zona afectada hay un único episodio de precipitaciones mientras que en la Comunidad Valenciana hay dos separados por 24 horas, entre las dos fases.

Las imágenes infrarrojas contienen información importante sobre las nubes, pero ofrecen pocos indicios sobre el contenido de vapor de agua. Las de vapor de agua indican el contenido de vapor de agua de niveles medio-altos de la troposfera y no nos ayudan a determinar la cantidad de precipitación que puede acumularse en tierra al no dar información sobre contenido de humedad en niveles bajos. 
Los instrumentos de microondas a bordo de los satélites polares permiten generar imágenes del contenido total de agua en columna (TPW). Este representa la profundidad del agua líquida que se acumularía si todo el vapor de agua contenido en un cilindro hipotético ubicado sobre un determinado lugar de la Tierra se condensara.

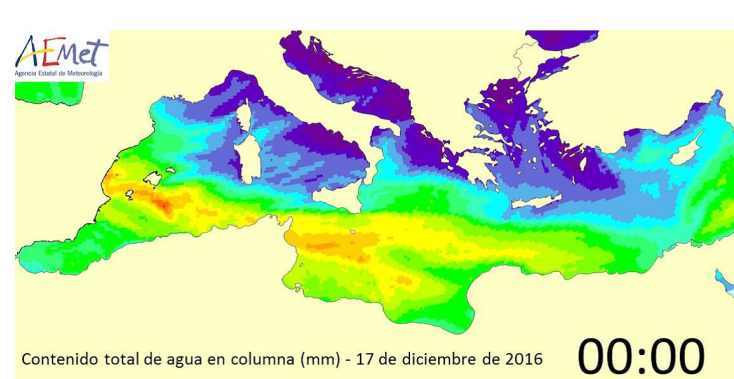

Figura 8. Contenido total de agua en la columna de la troposfera para el 17 de diciembre a las 00 . AEMET.
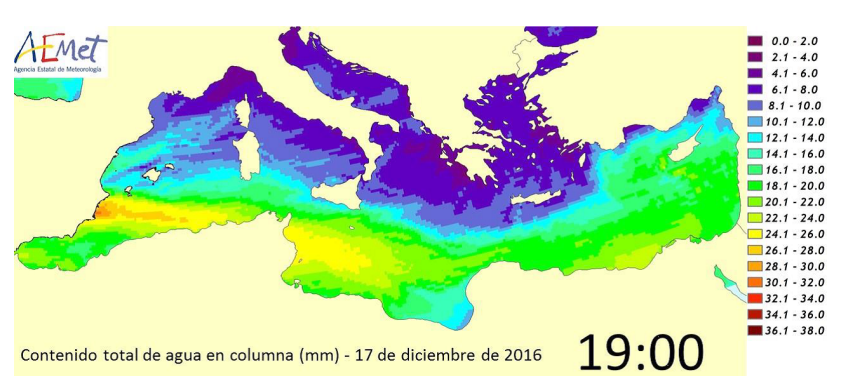

Figura 10. Contenido total de agua en la columna de la troposfera para el 17 de diciembre a las 19 . AEMET.

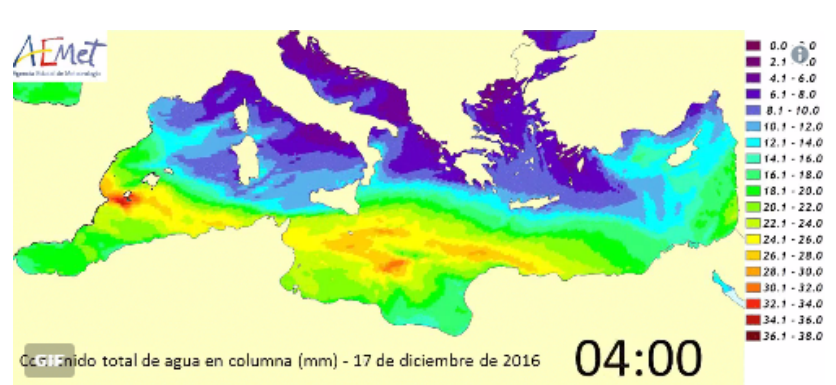

Figura 9. Contenido total de agua en la columna de la troposfera para el 17 de diciembre a las 04 . AEMET.

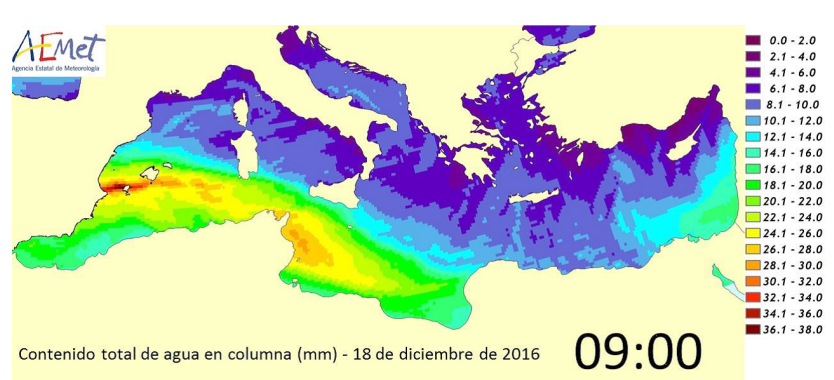

Figura 11. Contenido total de agua en la columna de la troposfera para el 18 de diciembre a las 09. AEMET.

El laboratorio de investigación del sistema Tierra (Earth System Research Laboratory, ESRL) de la NOAA define los ríos atmosféricos como estrechas bandas atmosféricas responsables de la mayor parte del transporte de humedad desde las regiones tropicales hacia los polos. En los productos TPW estas bandas son visibles como franjas de valores elevados.

En las imágenes, se ve el balanceo del «río de humedad» entre los días 16 al 18 de diciembre de 2016, con sus dos fases bien marcadas, de norte a sur y de sur a norte.

Un temporal en estas fechas tan avanzadas del año, ya casi en invierno, requiere un chorro de viento en capas bajas, es decir, un flujo de aire muy intenso en la baja troposfera. Mientras que en septiembre y a principios de octubre puede haber grandes lluvias simplemente con la inestabilidad termodinámica atmosférica, sin apenas viento, en fecha tan avanzada del año, el viento que canalice las precipitaciones hacia las montañas litorales y prelitorales es necesario.

En la figura 12 se puede ver el flujo de viento muy fuerte en la madrugada del día 19, cuando las precipitaciones en las sierras del norte de Alicante y sur de Valencia estaban siendo fuertes a muy fuertes y persistentes.

Por eso además de las lluvias, otro fenómeno destacado fue el viento. En la tabla 1 se relacionan las rachas más fuertes de viento durante el temporal de levante en la Comunidad Valenciana.

Como consecuencia del fuerte viento, la mar estuvo muy alterada, con olas que llegaron a tener una altura de 4,4 metros en el puerto de Valencia y de 4,3 metros en el de Alicante. 


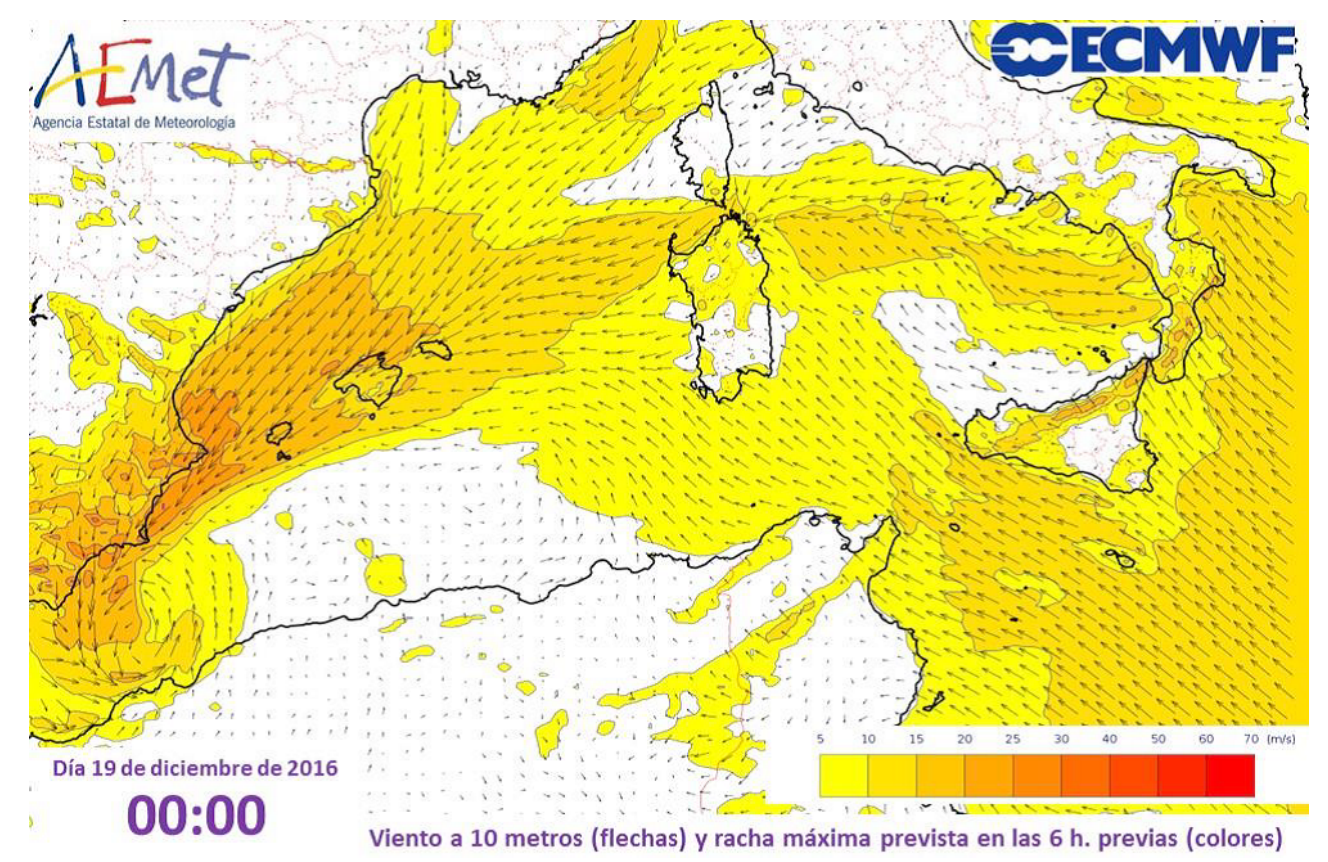

Figura 12. Predicción del modelo ECMWF para el 19 de diciembre a las 00 UTC del viento a 10 metros (flechas) y el valor de la racha máxima en las 6 horas previas (colores).

\begin{tabular}{|l|c|}
\hline \multicolumn{1}{|c|}{ Observatorio } & Racha máxima \\
\hline Barx & $96 \mathrm{~km} / \mathrm{h}$ \\
\hline Polinyà & $75 \mathrm{~km} / \mathrm{h}$ \\
\hline Aeropuerto Alicante & $74 \mathrm{~km} / \mathrm{h}$ \\
\hline Jávea / Xàbia & $74 \mathrm{~km} / \mathrm{h}$ \\
\hline Xàtiva & $73 \mathrm{~km} / \mathrm{h}$ \\
\hline Oliva & $72 \mathrm{~km} / \mathrm{h}$ \\
\hline Rojales & $71 \mathrm{~km} / \mathrm{h}$ \\
\hline Carcaixent & $70 \mathrm{~km} / \mathrm{h}$ \\
\hline
\end{tabular}

Tabla 1. Rachas máximas en la Comunidad Valenciana.

\section{DESCRIPCIÓN DE LAS PRECIPITACIONES DEL EPISODIO}

Pero lo más destacado del temporal fueron las precipitaciones, de forma que se puede encuadrar al temporal de diciembre de 2016 como uno de los grandes temporales de levante históricos en la Comunidad Valenciana por el volumen de precipitación registrado, similar a otros grandes temporales registrados en fecha más temprana del otoño.

Los máximos acumulados se han registrado en la montaña del sur de Valencia y norte de Alicante, donde en el episodio se han superado $\operatorname{los} 400 \mathrm{l} / \mathrm{m}^{2}$ en algunas localidades, y, lógicamente, cuando los máximos de precipitación se registran en zonas de montaña, surgen los problemas derivados de crecidas de ríos, ramblas, etc.

La característica más importante del temporal ha sido la persistencia. De los datos disponibles, en ninguna estación de la red la intensidad ha sido torrencial. Puntualmente la intensidad fue muy fuerte, con acumulados de entre $301 / \mathrm{m}^{2}$ y $601 / \mathrm{m}^{2}$ en menos de una hora, a última hora del domingo 18 , y en la madrugada del lunes 19 , en estaciones del sur de Valencia y norte de Alicante. 
El listado de precipitación acumulada en el episodio, entre el 16 y el 19 de diciembre de 2016 (día pluviométrico, de 7 a 7 UTC), en estaciones de la red de AEMET y de la Confederación Hidrográfica del Júcar se presenta en la tabla 2.

\begin{tabular}{|l|l|}
\hline Localidad & Total \\
\hline Beniarrés & 433,2 \\
\hline Pinet & 398,6 \\
\hline Orba & 379,7 \\
\hline Barx & 365,4 \\
\hline Millena & 356,0 \\
\hline Vall de Laguart & 332,8 \\
\hline Murla & 330,0 \\
\hline Muro de Alcoi & 322,8 \\
\hline Agres & 304,6 \\
\hline Ontinyent & 289,2 \\
\hline Moixent & 271,2 \\
\hline L'Adsubia & 263,4 \\
\hline Vall de Gallinera & 263,0 \\
\hline Navalón & 261,6 \\
\hline Enguera & 257,4 \\
\hline Vallada & 255,0 \\
\hline Buñol & 253,4 \\
\hline Antella & 253,0 \\
\hline Estubeny & 239,8 \\
\hline Carcaixent & 239,6 \\
\hline Bolbaite & 238,0 \\
\hline Siete Aguas & 233,2 \\
\hline Alfondeguilla & 212,4 \\
\hline
\end{tabular}

\begin{tabular}{|l|l|}
\hline Localidad & Total \\
\hline Alfondeguilla & 212,4 \\
\hline Càrcer & 210,6 \\
\hline Guadalest & 209,8 \\
\hline Villalonga & 209,0 \\
\hline Pilar de la Horadada & 208,0 \\
\hline Chiva & 207,0 \\
\hline Cortes de Pallás & 203,8 \\
\hline Teresa de Cofrentes & 201,6 \\
\hline Chera & 200,6 \\
\hline Alcoi & 197,2 \\
\hline Vva. de Castellón & 196,0 \\
\hline Bellús & 195,8 \\
\hline Navarrés & 185,6 \\
\hline Picassent & 172,6 \\
\hline Pego & 170,8 \\
\hline Picanya & 170,5 \\
\hline Tous & 168,0 \\
\hline Real de Montroy & 167,4 \\
\hline Bicorp & 163,8 \\
\hline Oliva & 154,1 \\
\hline Xàtiva & 152,8 \\
\hline Torrevieja & 151,1 \\
\hline Orihuela & 138,2 \\
\hline
\end{tabular}

\begin{tabular}{|l|r|}
\hline Localidad & Total \\
\hline Miramar & 130,0 \\
\hline Valencia & 128,3 \\
\hline Rojales & 122,4 \\
\hline Almenara & 120,1 \\
\hline Sagunt & 116,0 \\
\hline Benidorm & 111,2 \\
\hline Pinoso & 87,2 \\
\hline Alicante & 83,8 \\
\hline Elche & 80,4 \\
\hline Segorbe & 80,2 \\
\hline Castellón & 78,0 \\
\hline Villena & 75,4 \\
\hline Chelva & 74,0 \\
\hline A. Alicante/Elche & 73,1 \\
\hline Vilafranca & 72,4 \\
\hline Castellfort & 66,3 \\
\hline Novelda & 64,6 \\
\hline Torreblanca & 61,6 \\
\hline Montanejos & 51,4 \\
\hline Utiel & 51,0 \\
\hline Atz. del Maestrat & 50,8 \\
\hline Morella & 46,0 \\
\hline Fredes & 28,2 \\
\hline
\end{tabular}

Tabla 2. Precipitaciones acumuladas desde las 7 UTC del día 16 a las 7 UTC del día 19.

Datos registrados en las estaciones de AEMET y de la Confederación Hidrográfica del Júcar.

En la figura 13 se muestra el mapa de España con la precipitación acumulada en el episodio.

Y, finalmente, en la figura 14 se muestra el mapa de la Comunidad Valenciana con la precipitación acumulada para el mismo periodo que el mapa anterior.

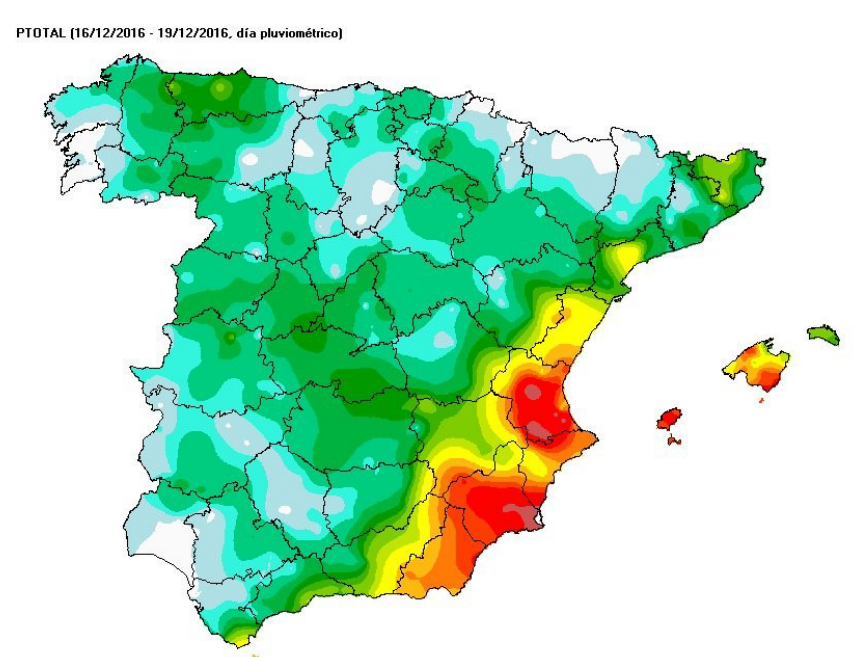

Figura 13.

Precipitación en 1/ $\mathrm{m}^{2}$ acumulada entre el 16 y el 19 de diciembre de 2016 (día pluviométrico, de 7 a 7 UTC).

Datos de las redes de AEMET y la Confederación Hidrográfica del Júcar. 

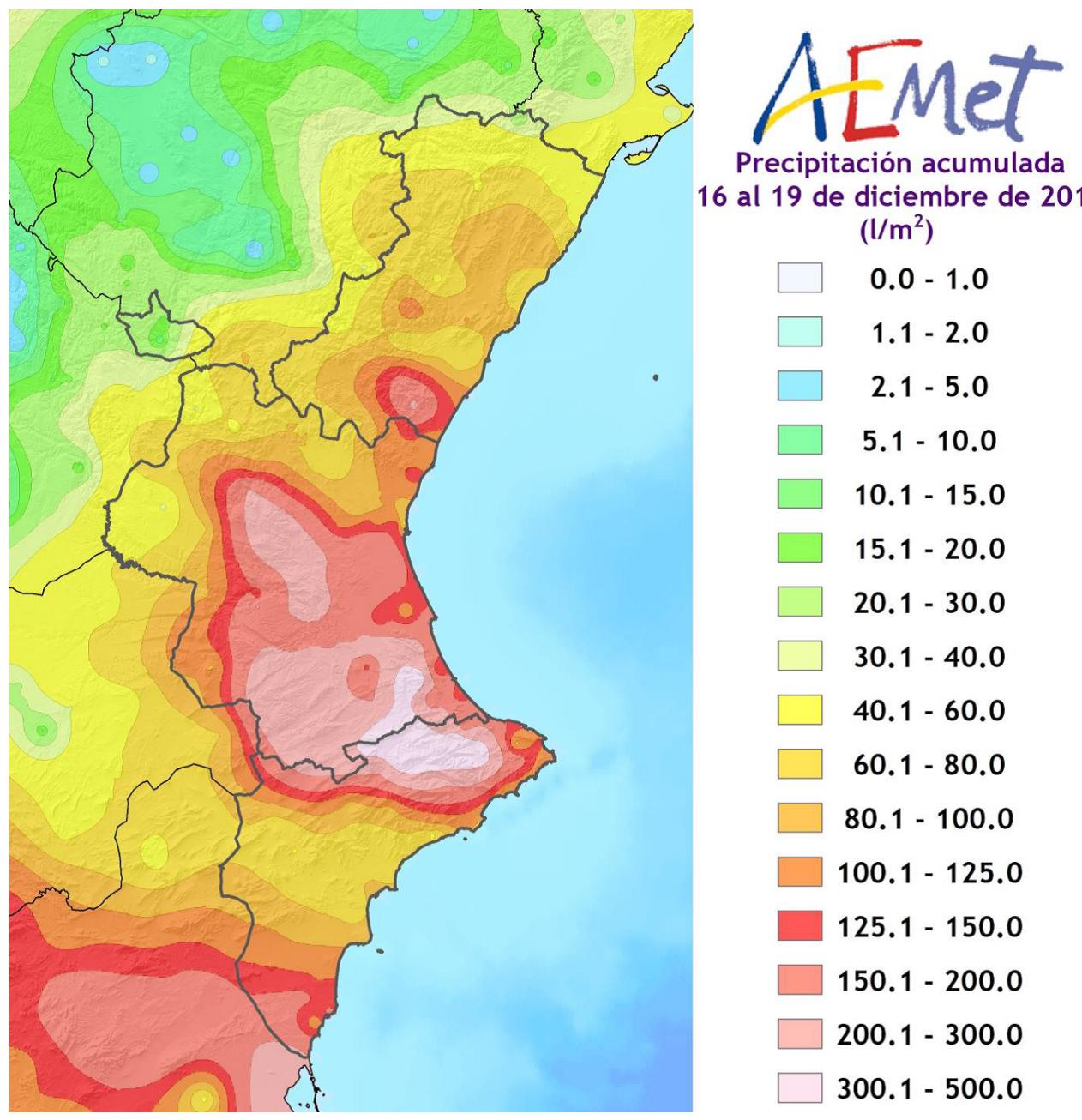

16 al 19 de diciembre de 2016 $\left(\mathrm{l} / \mathrm{m}^{2}\right)$

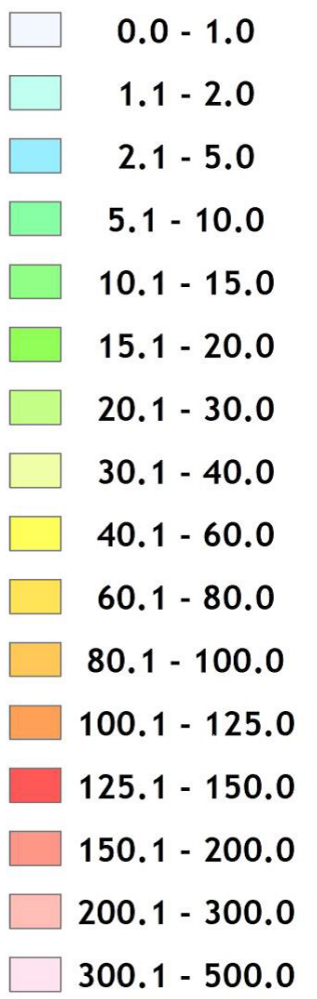

Figura 14. Precipitación en 1/ $\mathrm{m}^{2}$ acumulada entre el 16 y el 19 de diciembre de 2016 (día pluviométrico, de 7 a 7 UTC). Datos de las redes de AEMET y la Confederación Hidrográfica del Júcar.

\section{PREDICCIONES PROBABILÍSTICAS}

Dentro de las predicciones probabilísticas hay varias maneras de evaluar la bondad de esas predicciones. En este trabajo veremos dos: 1) probabilidad de que la precipitación prevista acumulada en 24 horas supere el umbral de los $20 \mathrm{~mm}$ para el día D+3, D+4 y D+5;2) altura prevista de olas por el mar de viento para el día $\mathrm{D}+2, \mathrm{D}+3$ y $\mathrm{D}+4$.

1) Analizaremos tres predicciones realizadas en tres momentos distintos:

$1 \mathrm{~A}$ - Viernes 16 a las 00 UTC para el domingo 18 (D+3), lunes $19(\mathrm{D}+4)$ y martes $20(\mathrm{D}+5)$.

1B - Viernes 16 a las 12 UTC para el lunes 19 (D+3), martes 20 (D+4) y miércoles $21(\mathrm{D}+5)$.

1C — Sábado 17 a las 00 UTC para el lunes 19 (D+3), martes 20 (D+4) y miércoles 21 (D+5).

1A Para el domingo 18, se puede observar una amplia zona con más de un $70 \%$ de probabilidad que abarca la isla de Ibiza y las provincias de Valencia, Alicante, Murcia y Almería oriental. El lunes 19 continuarían las precipitaciones desplazándose la zona con máxima probabilidad hacia el este, con un área de más del $70 \%$ de probabilidad afectando a las islas de Mallorca y Menorca y, en menor medida, a las provincias de Valencia y Alicante. 


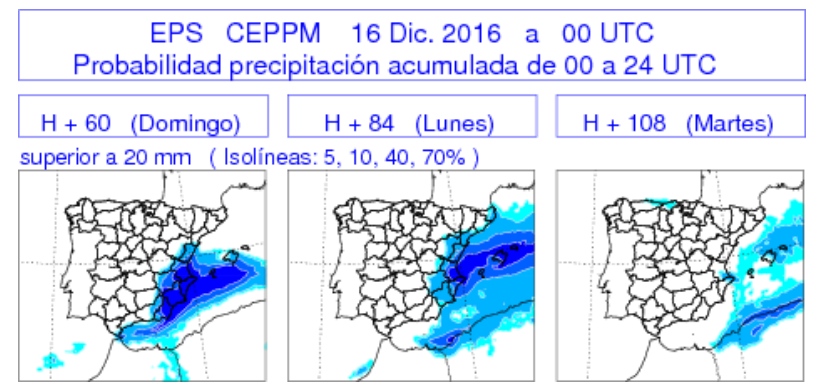

Figura 15.

Probabilidad de precipitación acumulada superior a 20 mm según el EPS del modelo ECMWF (CEPPM) del 16/12/2016 a las 00 UTC. Isolíneas de $5 \%$ (cian), $10 \%$ (azul claro), $40 \%$ (azul marino) y $70 \%$ (azul oscuro).

1B La predicción para el lunes 19 similar a la 1A para el mismo día. Para el martes hay cambios y aumenta la zona con una probabilidad mayor del $40 \%$ abarcando desde las islas hasta la costa catalana.

\section{MAPAS DE PROBABILIDAD // Pasada: 16 Dlc. 2016 a 12 UTC Precipltacion acumulada en 24 horas (de 0 a $24 \mathrm{Z}$ ) \\ $\mathrm{D}+3$ (Lunes) $\mathrm{D}+4$ (Martes) $\mathrm{D}+5$ (Miercoles)} Precipitacion superior a $20 \mathrm{~mm}(5,10,40,70)$
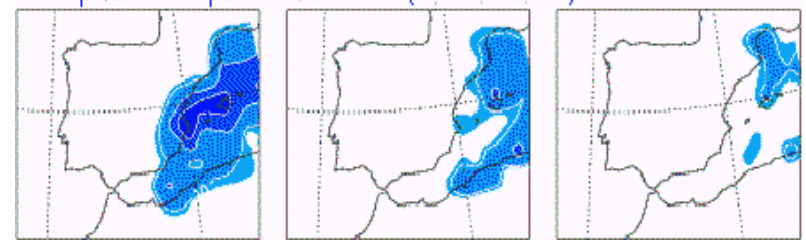

Figura 16.

Probabilidad de precipitación acumulada superior a 20 mm según el EPS del modelo ECMWF (CEPPM) del 16/12/2016 a las 12 UTC. Isolíneas de $5 \%$ (cian), $10 \%$ (azul claro), $40 \%$ (azul marino) y $70 \%$ (azul oscuro).

1C El área con mayor probabilidad se mantiene sin cambios centrada en Baleares, Valencia y Alicante para el lunes 19. Para el martes 20, confirma el desplazamiento de la precipitación hacia Cataluña. Para el miércoles 21 se prevé la finalización del temporal de precipitación.

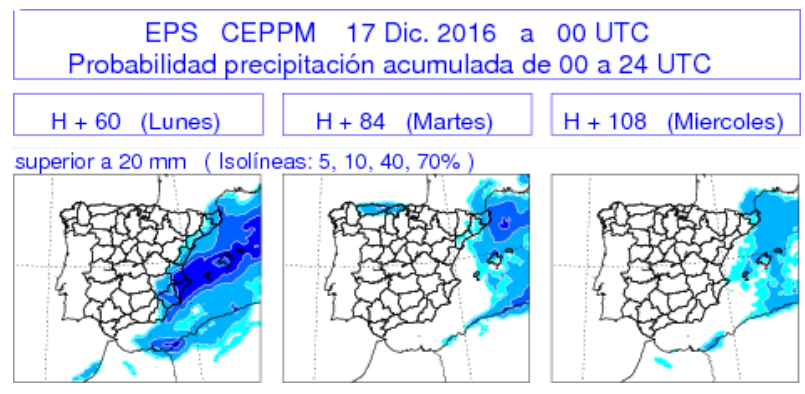

Figura 17.

Probabilidad de precipitación acumulada superior a 20 mm según el EPS del modelo ECMWF (CEPPM) del 17/12/2016 a las 00 UTC. Isolíneas de $5 \%$ (cian), $10 \%$ (azul claro), $40 \%$ (azul marino) y $70 \%$ (azul oscuro).
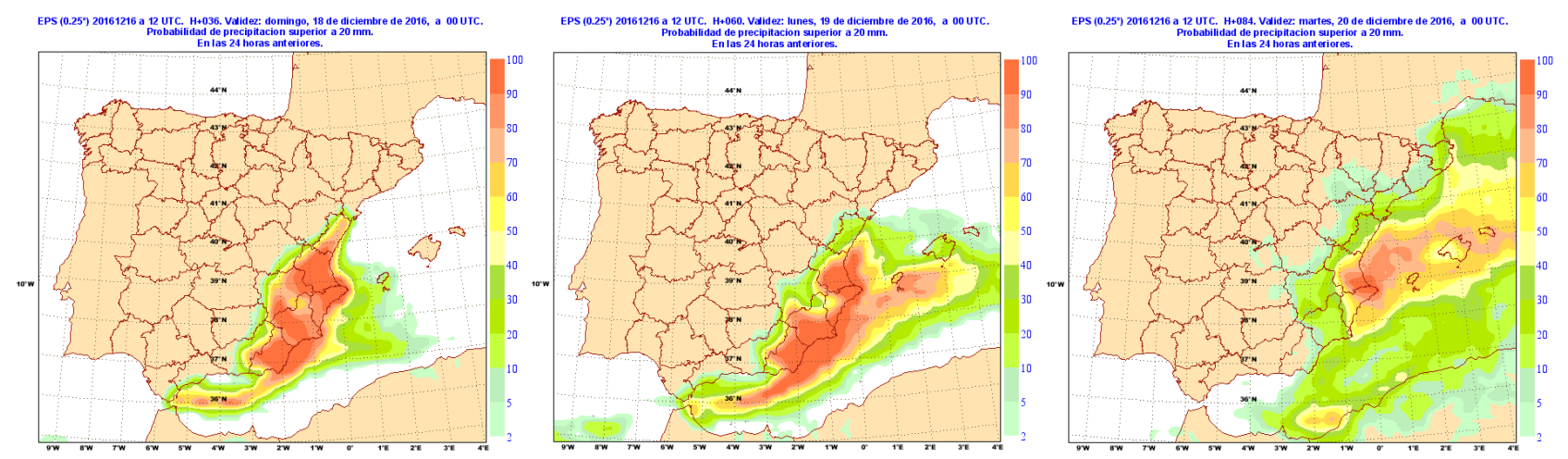

Figuras 18 (izquierda), 19 (centro) y 20 (derecha).

Predicción probabilística con EPS $\left(0,25^{\circ}\right)$ del CEPPM de probabilidad de precipitación acumulada superior a $20 \mathrm{~mm}$ para el sábado día $19(\mathrm{D}+2)$, domingo día $20(\mathrm{D}+3)$ y lunes $21(\mathrm{D}+4)$ respectivamente.

La escala de probabilidad, situada a la derecha de las figuras va desde 2 (azul) hasta $100 \%$ (rojo). 
2) La predicción probabilística de altura de olas por el mar de viento del 16 a las 00 UTC para D+2 (sábado), D+3 (domingo) y D+4 (lunes). No hay previsión de altura de olas superior a $4 \mathrm{~m}$ en ninguna zona, excepto para el sábado que, con una probabilidad mínima del 10\%, da una pequeña zona entre Ibiza y Alicante.

La predicción probabilística para el viento, y por tanto para el oleaje, ya que este es totalmente dependiente del viento, se queda claramente por debajo de las olas observadas (4,2-4,3 m). La probabilidad de olas de más de $4 \mathrm{~m}$ a 36 horas vista es insignificante. Esto es así, porque probablemente el modelo infravalora la profundidad de la ciclogénesis al no tener suficientemente en cuenta la contribución de la liberación de calor latente de condensación que se realiza en una escala espaciotemporal menor que la contribución dinámica.

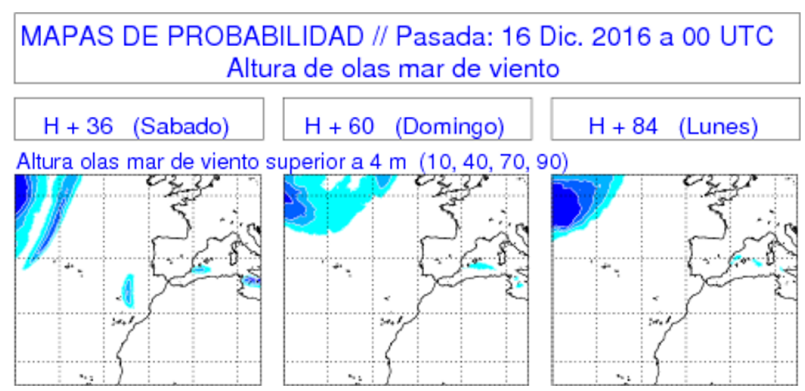

Figura 21.

Probabilidad de altura significativa de las olas superior a 4 m según el EPS del modelo ECMWF (CEPPM). Isolíneas de $5 \%$ (cian), $10 \%$ (azul claro), $40 \%$ (azul marino) y $70 \%$ (azul oscuro).

\section{CONCLUSIONES}

El temporal de los días 16 al 19 de diciembre fue muy adverso en el litoral mediterráneo de la Península, tanto en las precipitaciones como en el viento y el oleaje en el litoral.

Además de las causas de la génesis del temporal y su desarrollo, en este trabajo se han analizado productos de modelos probabilísticos procedentes del Centro Europeo de Predicción a Plazo Medio, ya que cuando existe la probabilidad de que en los próximos días se puede desarrollar un temporal especialmente adverso, con serias consecuencias para las infraestructuras y cierto riesgo para la población, la cuantificación de esa probabilidad es una herramienta fundamental para orientar a las autoridades, a los responsables de protección civil y población en general.

La probabilidad de las precipitaciones acumuladas está bien prevista por los productos probabilísticos del CEPPM tanto en las áreas afectadas como en el intervalo temporal previsto, con la única salvedad que el umbral de 20 mm es demasiado bajo para la acumulación de precipitación que se da en este tipo de episodios.

Respecto al viento y el oleaje la predicción probabilística sí que es claramente inferior a la registrada debido a que intervienen factores que el modelo no tiene suficientemente en cuenta.

\section{REFERENCIAS}

Armengot SerRano, R., 2002. Las lluvias intensas en la Comunidad Valenciana. Ministerio de Medio Ambiente, Madrid.

Cordeira, J. M., Ralph, F. M. y Moore, B. J., 2013. The development and evolution of two atmospheric rivers in proximity to western North Pacific tropical cyclones in October 2010. Mon. Wea. Rev., 141, 4234-4255, doi:10.1175/MWR-D-13-00019.1. 
GuAN, B. y WaLISER, D. E., 2015. Detection of atmospheric rivers: Evaluation and application of an algorithm for global studies. J. Geophys. Res. Atmos., 120, 12514-12535, doi:10.1002/2015JD024257.

Neiman, P. J., Ralph, F. M., Wick, G. A., Lundquist, J. D. y Dettinger, M. D., 2008. Meteorological characteristics and overland precipitation impacts of atmospheric rivers affecting the West Coast of North America based on eight years of SSM/I satellite observations. J. Hydrometeor., 9, 22-47, doi:10.1175/ 2007JHM855.1.

RalPh, F. M., NeIMAN, P. J. y Wick, G. A., 2004. Satellite and CALJET aircraft observations of atmospheric rivers over the eastern North Pacific Ocean during the winter of 1997/98. Mon. Wea. Rev., 132, 1721-1745, doi: 10.1175/1520-0493(2004)132<1721: SACAOO>2.0.CO;2.

Riesco Martín, J. y Alcover Ronda, V., 2003. Predicción de precipitaciones intensas de origen marítimo mediterráneo en la Comunidad Valenciana y la Región de Murcia. Ministerio de Medio Ambiente, Madrid.

Zhu, Y. y Newell, R. E., 1998. A proposed algorithm for moisture fluxes from atmospheric rivers. Mon. Wea. Rev., 126, 725-735, doi: 10.1175/1520-0493(1998)126<0725: APAFMF>2.0.CO;2. 